\title{
Essentialist Blindness Would Not Preclude Counterfactual Knowledge
}

\section{Sònia Roca-Royes}

\section{(2) OpenEdition \\ 1 Journals}

\section{Electronic version}

URL: http://journals.openedition.org/philosophiascientiae/745

DOI: 10.4000/philosophiascientiae.745

ISSN: $1775-4283$

\section{Publisher}

Éditions Kimé

\section{Printed version}

Date of publication: 1 October 2012

Number of pages: 149-172

ISBN: 978-2-84174-592-0

ISSN: 1281-2463

\section{Electronic reference}

Sònia Roca-Royes, «Essentialist Blindness Would Not Preclude Counterfactual Knowledge », Philosophia Scientiæ [Online], 16-2 | 2012, Online since 01 October 2015, connection on 03 November 2020. URL : http://journals.openedition.org/philosophiascientiae/745 ; DOI : https://doi.org/10.4000/ philosophiascientiae.745 


\title{
Essentialist Blindness Would Not Preclude Counterfactual Knowledge
}

\author{
Sònia Roca-Royes \\ University of Stirling (Scotland, UK)
}

Résumé : L'objectif de cet article est double. Il défend d'abord, contre une menace potentielle, la thèse selon laquelle une capacité pour la connaissance essentialiste ne doit pas figurer parmi les capacités fondamentales pour la connaissance des contrefactuels. Il évalue ensuite une conséquence de cette thèse, ou du moins de la défense que j'en fais qui s'appuie sur une discussion des théories de Kment et de Williamson portant sur le lien entre la modalité et les contrefactuels.

Abstract: This paper does two things. First, it defends, against a potential threat to it, the claim that a capacity for essentialist knowledge should not be placed among the core capacities for counterfactual knowledge. Second, it assesses a consequence of that claim-or better: of the discussion by means of which I defend it-in relation to Kment's and Williamson's views on the relation between modality and counterfactuals.

\section{Introduction and aims}

Understood as what it is-an existential claim-it is safe to assume that we have counterfactual knowledge. This claim would be true even if we only knew a few trivial counterfactuals like: If I were there, I would be there. It is also uncontroversial that we have non-trivial counterfactual knowledge. I know that if I were a seven-year-old human, I would have blood. Although I haven't flipped the $£ 1$ coin in my pocket, I know that if I had flipped it, it would most likely end up in tails or heads. I know that if I ate an Amanita phalloides, I would be severely poisoned. I know also that, in the scenario Williamson describes in [Williamson 2007, 142], if the bush hadn't been there, the rock would have ended in the lake. When I say that it is uncontroversial that we know those counterfactuals, I intend to be understood as saying that, mostly, it's those who 
are sceptic about counterfactual knowledge in general that would find their knowability controversial.

But there are counterfactuals whose knowledge (or knowability) is controversial even among the non-sceptics. I distinguish two sorts. First, there are counterfactuals the controversy around whose knowledge (or knowability) is inherited from local controversies elsewhere. Do we know the content of Goldbach's Conjecture? Controversy here will translate into controversy as to whether we know the counterfactual: "If Humphrey had won the elections, every even integer greater than two could be expressed as the sum of two primes". Do we know whether humans are essentially so? Controversy here will translate into controversy as to whether we know the counterfactual: "If Wittgenstein and Betty Hutton had had a child in common, s/he would be essentially human". ${ }^{1}$ Second, there are counterpossibles. The controversy around the knowledge (or knowability) of counterpossibles is the (socio-epistemological) consequence of a philosophical disagreement among epistemic peers. If Nicotine-the yucca plant in my office-were human, she would not have blood. Is this so? Hereunder the assumption that (it is agreed that) Nicotine cannot, metaphysically, be a human being - the controversy is served. Those who-for whichever theoretical reasons-think that all counterpossibles are vacuously true would say 'yes' whereas those who allow-also for whichever theoretical reasons-for false counterpossibles would most likely say 'no, Nicotine would have blood if she were human'.

I have two related goals in this paper. First, to motivate the negative answer to the following question: Would our (hypothetical) blindness to the essentiality of essential facts-'essentialist blindness' henceforth—preclude knowledge of all or most counterfactuals (including most uncontroversial ones)? ${ }^{2}$ The second aim is to assess a certain consequence of such negative answer. I'll achieve my first aim by defending $(i)$ over $(\neg i)$ :

(i) Our epistemology of counterfactuals should not place the capacity for essentialist knowledge among the core capacities for counterfactual knowledge.

$(\neg i)$ Our epistemology of counterfactuals should place the capacity for essentialist knowledge among the core capacities for counterfactual knowledge.

I won't offer a precise characterisation of the distinction between core capacities for counterfactual knowledge and counterfactual-specific capacities. Instead, a vague characterisation should suffice. A capacity for mathematical knowledge is deployed in acquiring (first hand) knowledge of: "If two men and two women

1. The existence of this sort of controversial counterfactuals is one consequence of the fact that, as Williamson says: "In general, our capacity to evaluate counterfactuals recruits all our cognitive capacities to evaluate sentences" [Williamson 2007, 152].

2. By 'uncontroversial counterfactual' I mean counterfactual whose knowability is uncontroversial. 
had come to the party, four people would have come." If that capacity is deployed in acquiring knowledge of most counterfactuals-including most uncontroversial ones-it is a core capacity. If, for most counterfactuals, that capacity is not deployed in acquiring knowledge of them, it is instead a counterfactualspecific capacity. Similarly for any capacity that is deployed in acquiring knowledge of (at least) some counterfactual. These hints as to how to understand the distinction don't provide a clear cut-off line. For current purposes, it won't harm to leave things underdetermined.

It is none of my current aims to argue that there are core capacities for counterfactual knowledge. Instead, the paper is confined to doing the two things anticipated above. First, to argue for $(i)$-independently of what's the case with other capacities-and, second, to assess a certain consequence of it.

Why, however, should one invest efforts in defending $(i)$ ? I intend this question to have two dimensions. First, why is it important to secure $(i)$ ? Second, who am I arguing against? I address them in turn.

The prospects of a satisfactory epistemology of essence are-we have reasons to believe-worse than those of a satisfactory epistemology of counterfactuals. The truth of $(\neg i)$, however, would make the epistemology of essence a constitutive part of a general epistemology of counterfactuals. It is desirable to have reasons against this dependence so that the possibility of progress in the epistemology of (the knowable) counterfactuals is justifiably believed to be immune to our failures in the epistemology of essence. In a similar vein, that we have essentialist knowledge is controversial. The truth of $(\neg i)$ would force us to transfer this controversy onto most claims to counterfactual knowledge. It is desirable to have reasons not to have to do this. In this context, it is of value to argue that the robustness of our claim to counterfactual knowledge is independent of the robustness (or else weakness) of our claim to essentialist knowledge.

But can't we just take ( $i$ ) for granted? This brings me to the second dimension of the question. I think that (i) is exceedingly plausible and that one should be allowed to take it as the default claim. Provided-and here comes an important qualification - that there are no threats to it. As it turns out, there are threats to it that one would do well, I think, not to overlook. These threats come in the form of a suspicion that $(\neg i)$ might be true and which arises from the works of Kment [Kment 2006] and Williamson [Williamson 2007]. To prevent misunderstanding, let me emphasize that I attribute $(\neg i)$ neither to Kment nor to Williamson. The claim is rather that their works provide grounds for thinking that $(\neg i)$ might be true. I want to undermine those grounds.

Even granting that Kment and Williamson do not (explicitly at least) endorse $(\neg i)$, would their views be somehow affected in the event that my post-threat vindication of $(i)$ were persuasive? It is assessment of the consequences of $(i)$ as far as this question is concerned that is my second goal. To anticipate: the reasons I shall offer to vindicate (i) will reveal what I believe to be argumentative 
gaps in each of their accounts on the relation between modality and counterfactuals.

The structure of the paper is as follows. In $\S 2$, I construct the threat to (i) that emerges from the works of Kment and Williamson. In § 3 , I argue that the case does not survive scrutiny and vindicate $(i)$. In $\S 4$, I articulate the argumentative gaps in Kment's and Williamson's accounts that the discussion in $\S 3$ appears to reveal.

In what follows, I make heuristic use of worlds and scenarios (whether possible or impossible). I also assume that we have (at least) uncontroversial nontrivial counterfactual knowledge.

\section{The two-horn case against ( $i$ )}

In this section, I present the two-horn (prima facie) case for $(\neg i)$. The structure of the case is as follows. Assuming that there are false counterpossibles-the first horn-I formulate (emr-1); a general rule for counterfactual reasoning that would be very reliable on this horn's assumption. Assuming that all counterpossibles are vacuously true-the second horn-I formulate (emr-2); a general rule for counterfactual reasoning that would be very reliable on this horn's assumption. Kment endorses the content of the first assumption and Williamson that of the second. Partly on the basis of their views, both (emr-1) and (emr2) could easily be thought to require, if we are to follow them in an informed manner, (the proper exercise of) a capacity for essentialist knowledge in evaluating most counterfactuals. Either there are false counterpossibles or there aren't. The two-horn (prima facie) case that emerges from here is that, whether or not there are false counterpossibles, a capacity for essentialist knowledge would be a core capacity.

I begin with some preliminary remarks on the relation between counterfactual truth and counterfactual knowledge.

According to (the thinnest expression of) the minimality requirement at the level of truth-conditions, the worlds that are relevant to the truth or falsity of $(P \square \rightarrow Q)$ are the closest $P$-worlds. ${ }^{3}$ Disagreements arise, however, as to what exactly the extension of the closeness relation is; that is, on which differences among worlds contribute more to overall similarity than which others. It is widely agreed that, given two worlds, $w$ and $w^{\prime}$, a draw in the number of same facts that $w$ and $w^{\prime}$ share with the actual world need not mean a draw in their overall similarity. Instead, which are the same facts can make a difference. And once one is in the business of weighting similarities, the options are several as to which (kinds of) facts are (thought to be) heavier than which others. I shall not

3. I assume, for simplicity and pace some doubts to the contrary expressed by Lewis [Lewis 1973, § 1.4], that there always are closest worlds. 
commit myself to any detailed weighting system. I will only assume that (kinds of) worlds are ordered as follows: ${ }^{4}$

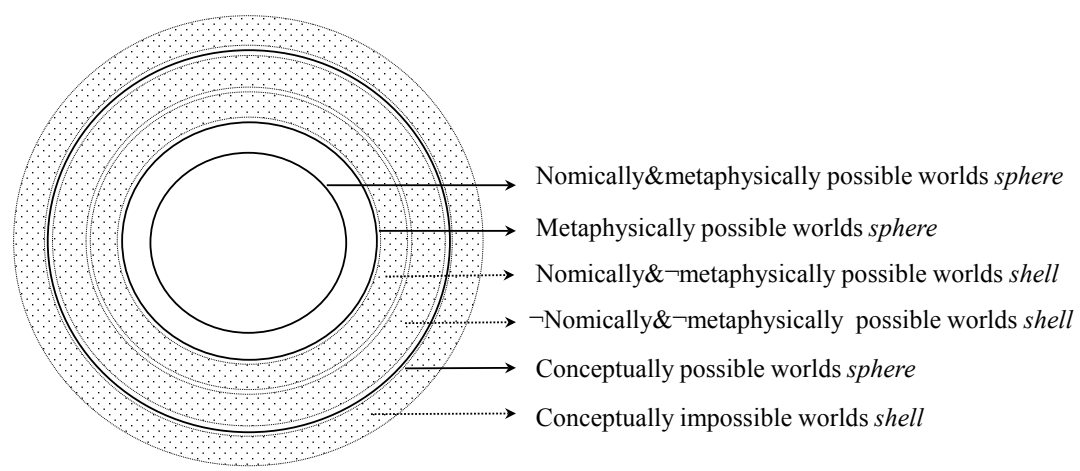

Graphic 1

My assuming Graphic 1 does not beg the question against those who (would) believe in fewer kinds of worlds than represented here. One just needs to delete as many circles as necessary until one is left with a representation that mentions only those kinds of worlds one believes in. Someone like Lewis would only keep the two smallest circles, whereas someone like Nolan would arguably keep them all. The assumption does not rule out conflation of circles either. All the assumption rules out is this: the order-inversion of any two rings that represent worlds one would believe in. So understood, this is not an uncommon thing to assume and, at any rate, it is something Kment endorses ${ }^{5}$ [Kment 2006, 258259] and Williamson gives us no reason to think he denies.

Now, the minimality requirement at the level of truth-conditions involves a consistency bit and a maximal similarity bit. It amounts to the claim that the closest worlds are those consistent worlds (provided the antecedent is consistent) that are as similar to the actual world as the truth of the antecedent of

4. As the graphic suggests, a (non-empty) class of metaphysically impossible worlds that nonetheless satisfy all the actual laws of nature should be recognized. A world where Stuart Mill is a satisfied pig but that is qualitatively exactly like the actual world belongs to this category. I am calling these worlds 'metaphysically impossible yet nomically possible'. Kment-who takes the nomically possible worlds to be "just those metaphysically possible worlds that have the same laws of nature as the actual world" [2006, 261; my emphasis]—would need to call them something else. But he presumably would not neglect the existence of such (non-empty) category. To that extent, the disagreement here is merely terminological.

5. Though not fully explicitly, since-terminological discrepancies aside (see previous footnote) - he does not explicitly distinguish between the two shells within the shell of the metaphysically impossible (but conceptually possible) worlds. 
the counterfactual at hand allows. What the counterfactual facts are depends on what the similarity order is. And how capable we are of counterfactual knowledge depends on how capable we are of tracking the similarity order. The existence of non-trivial counterfactual knowledge implies that, in hypothetical reasoning, and to some extent, we operate constrained by an epistemic counterpart of the minimality requirement which, in evaluating $(P \square \rightarrow Q)$, sufficiently reliably leads us to consider what in fact are the closest $P$-worlds. In agreement with Kment, "hypothetical reasoning needs to be based on rules that permit us to determine which propositions are cotenable with a given antecedent" [Kment 2006, 288].

Which, then, are these rules? First, how they should not look like. A rule that simply asked "consider consistent $P$-scenarios" would be a very unreliable guide to counterfactual knowledge. For, for most true counterfactuals, $(P \square \rightarrow Q)$, there are different ways of preserving consistency some of which do not satisfy the minimal alteration bit and falsify $Q$. The Amanita phalloides counterfactual illustrates this, and other examples are not difficult to come by. And a rule that didn't go beyond "consider consistent $P$-scenarios maximally similar to the actual world" would not be operationally effective unless it came with an indication as to what counts as a maximally similar world (i.e., as to what counts as a minimal change). How, then, would a reliable and operationally effective rule look like? There are two most natural answers to this question, depending on whether or not one believes that there are false counterpossibles. And, as anticipated, each of them allows for the construction of a case against $(i)$, which is what generates the two-horn case against it. Let me consider them in turn.

Assume first that some counterpossibles are false-and that there are impossible worlds. Counterpossible (1) is a plausible candidate to be false under these assumptions:

(1) If Nicotine were human $[P]$, she would not have blood $[Q]$.

Arguably, there are impossible worlds that are nonetheless logically consistent. Among them, some are $P \& \neg Q$-worlds and some are $P \& Q$-worlds. It is safe to assume that all $P \& Q$-worlds are further away from actuality than some $P \& \neg Q$ world, which renders (1) false. Initial Reason: Since we are to preserve consistency, Nicotine being human (i.e., $P$ ) makes "Nicotine is not human" noncotenable. The law-like fact that all humans have blood, however, remains cotenable. So it must stay-by the minimality bit. So human-Nicotine has blood and (1) is false. Complaint: In fact, therefore, Nicotine being human makes noncotenable "Nicotine is not human" and "Nicotine has no blood". That's two items. Why should these two items go away as opposed to these other two: "Nicotine is not human" and "All humans have blood"? The assumption that worlds are ordered as in Graphic 1, together with some further views of Kment, provides an answer to this complainer. 
By looking at that graphic, we can see that, at the level of truth-conditions, and other things being equal, ${ }^{6}$ sameness of conceptual truths is the heaviesti.e., any world that violates as few as one of them is automatically placed at the furthest shell-followed by sameness of metaphysical necessities, followed by sameness of laws of nature, and followed by sameness of non-mathematical particular facts. ${ }^{7}$ The metaphysical necessities, according to Kment, are whatever is implied by the conceptual truths, the mathematical truths and the conditionalized essential truths. A conditionalized essential truth about $x$ is an essential truth about $x$ conditionalized on $x$ 's existence. For instance, if water exists, it is composed of $\mathrm{H}_{2} O{ }^{8}{ }^{8}$ (The reason why Kment speaks of conditionalized essential truths is to allow for essential yet contingent truths-e.g. water is composed of $\mathrm{H}_{2} \mathrm{O}$-whose contingency would be inherited from the contingency of the entities they are about-e.g. water.) Now, the two options that the complainer puts on the table are different as to whether to delete "Nicotine has no blood" or "All humans have blood". Assuming that the latter is a biological necessity, it is the former that should go, since it is a (non-mathematical) particular fact. ${ }^{9}$ This is the rejoinder that we can construct assuming Graphic 1 and the other views of Kment involved.

On these assumptions, the following epistemic minimality requirementwhich closely mimics (a thicker expression of) the minimality requirement at the level of truth-conditions-is, among the reliable and operationally effective guides to counterfactual knowledge, ideally informative:

(emr-1) When evaluating ( $P \square \rightarrow Q$ ), imagine away as few truths as possible compatibly with complying with:

(a) Preserve consistency; ${ }^{10}$ and

(b) Imagine away $p 1$ over $p 2$ whenever:

(b.1) $p 1$ is a non-mathematical particular fact and $p 2$ is a nomic or a mathematical or a conditionalized-essential or a conceptual fact.

\footnotetext{
6. In Kment's case: "other explanatory facts being equal".

7. I include the qualification 'non-mathematical' here partly to follow Kment as closely as possible (see $\left(R_{M}\right)$ below in the main text). But also for independently good reasons: While some mathematical facts are particular, they are (agreed to be) necessary and, as such, heavier than particular facts about contingent entities. What to do with particular facts about other abstract entities (like, perhaps, fictional characters) arguably depends on whether these entities are contingent or necessary. For the sake of attempting to start making progress at all with the current discussion, I leave this debate at one side. I believe that the arguments can be adapted if other qualifications are believed to be necessary.

8. N.B.: An essential truth-e.g., (allegedly) water is composed of $\mathrm{H}_{2} \mathrm{O}$-should not be confused with an essentialist truth-e.g. water is essentially composed of $\mathrm{H}_{2} \mathrm{O}$.

9. Despite being arguably essential, it is a non-mathematical particular fact and, therefore, it is less heavy than a natural law.

10. Doable only when $P$ is not logically contradictory itself.
} 
(b.2) $p 1$ is a nomic fact and $p 2$ is a mathematical or a conditionalized-essential or a conceptual fact.

(b.3) $p 1$ is a mathematical or a conditionalized-essential fact and $p 2$ is a conceptual fact. ${ }^{11}$

If $p 1$ and $p 2$ are of the same kind, it won't make a difference to overall similarity which one you imagine away.

Kment-who believes in false counterpossibles-comes very close to endorsing (emr-1) explicitly. As mentioned above, he thinks that hypothetical reasoning needs to be based on rules that permit us to determine which propositions are cotenable with a given antecedent. He adds to this that " $\left(R_{M}\right)$ is such a rule" [Kment 2006, 288]. Consistency permitting, $\left(R_{M}\right)$ requires us to hold fixed all mathematical and conditionalized essential truths:

$\left(R_{M}\right)$ Analytically consistent worlds in which all actual mathematical and conditionalized essential truths hold are closer to the actual world than all other worlds. [Kment 2006, 269]

Similarly, $\left(R_{N}\right)$ —consistency permitting-requires us to hold fixed all nomic facts as well:

$\left(R_{N}\right)$ Analytically consistent worlds in which all actual mathematical and conditionalized essential truths hold, and which have the same laws of nature as the actual world, are closer to the actual world than all other worlds. [Kment 2006, 269]

And an analogous rule, $\left(R_{C}\right)$-though Kment does not formulate it explicitlywould require us to hold fixed all conceptual truths too:

$\left(R_{C}\right)$ Analytically consistent worlds are closer to the actual world than all other worlds.

The difference between $(e m r-1)$ and $\left(R_{N}\right)+\left(R_{M}\right)+\left(R_{C}\right)$-when taken as rules that govern hypothetical reasoning-virtually reduces to a difference in form. Let us grant for now that our counterfactual reasoning is based on a rule akin to this.

How does it bear on $(\neg i)$ ? Kment thinks, first, that "applications of $\left(R_{M}\right)$ in hypothetical reasoning are very common" [Kment 2006, 289, my emphasis] and, second, that, when one wants to apply $\left(R_{M}\right)$ when evaluating $(P \square \rightarrow Q)$, one needs to proceed in two steps: (1) to determine whether $P$ is metaphysically possible and, if it is, (2) to determine which propositions are the metaphysically necessary truths in order to (knowledgably) hold them all fixed. He concludes that:

11. This clause must (and can) be included only if mathematical and essential truths are believed not to be conceptual truths. 
Determining whether a given antecedent [is metaphysically possible] is thus a routine task that speakers face when applying $\left(R_{M}\right)$. [...]

Determining whether a proposition [is metaphysically necessary] is therefore a routine task in evaluating counterfactuals. [Kment 2006, 289, my emphasis]

One might wonder why Kment thinks that determining whether something is metaphysically possible [or necessary] is a step in our applications of $\left(R_{M}\right)$; for the former involves the properties of metaphysical necessity and possibility while $\left(R_{M}\right)$ mentions mathematical and conditionalized-essential truths instead. Given what he takes the necessary truths to be, the short answer is that determining whether an analytically consistent proposition is metaphysically necessary just is determining whether it is implied by the mathematical and the conditionalized essential truths; and determining whether an analytically consistent proposition is metaphysically possible just is determining whether it is compatible with the mathematical and the conditionalized essential truths plus their corresponding minor premises. (See [Kment 2006, 288-289] for the details.) Equally routinely, therefore, we would need to deploy a capacity for essentialist knowledge in counterfactual reasoning.

Now, I'm not in a position to say that 'routinely', in the context of Kment's views, implies 'often enough as to imply $(\neg i)$ ', and this is why I don't attribute $(\neg i)$ to him. Yet, his 'routine'-claim certainly provides enough grounds for a prima facie case against $(i)$ that no one who believes in false counterpossibles and grants Graphic 1 should overlook. In § 3, I will provide the reasons on which I believe this case can be undermined. Before that, I turn next to the second horn; the one that, relying on Williamson's work, can be constructed under the assumption that all counterpossibles are vacuously true.

$(e m r-1)$ encodes a cotenability priority order that only those committed to false counterpossibles—and to impossible worlds if to worlds at all—could be happy with. Let me explain why this is so, and then identify an alternative cotenability priority order that someone who believes that all counterpossibles are vacuously true could be happy with. Consider (1) again:

(1) If Nicotine were human $[P]$, she would not have blood $[Q]$.

And consider a semantics for counterfactuals with only metaphysically possible worlds. Graphic 2 in the next page illustrates this case.

According to one such semantics, (1) is vacuously true: there is no (possible) world where Nicotine is human (and has blood). Yet, if, in hypothetical reasoning, we followed (emr-1), we would judge (1) to be false. On the basis of clause (a), we would preserve consistency; and, on the basis of (b.1), we would imagine away: "Nicotine does not have blood" $(p 1)$ in favour of keeping "all humans have blood" $(p 2)$. On one such semantics, therefore, $(e m r-1)$ is a highly unreli- 
Nomically possible worlds

Metaphysically possible worlds

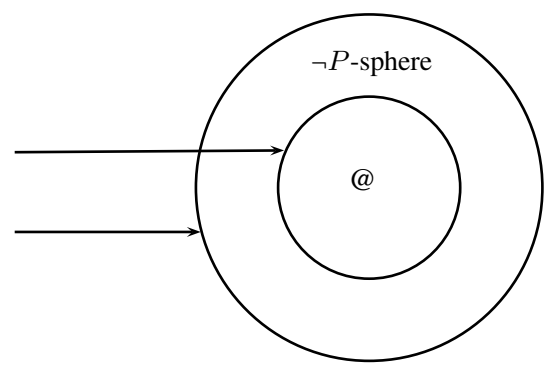

Graphic 2

able guide to counterpossible knowledge. ${ }^{12}$ If, by contrast: "Nicotine is human" (the antecedent of (1)) and "Nicotine is a plant (and therefore not human)"which, let us assume, is an actual and essential truth-were both deemed cotenable, their being jointly inconsistent could provide (access to) the vacuous truth of (1); her not having blood would trivially follow.

Let me generalize. Every counterpossible-by definition, a counterfactual with metaphysically impossible antecedent-contradicts some (nonconditionalized) essential fact. On this basis, the easiest way to secure our sensitivity to the vacuous truth of counterpossibles would be by means of a rule that, in hypothetical reasoning, requires us to always hold essential facts fixed (conditionalized or not) irrespective of the antecedent. Not surprisingly, this is what Williamson-who thinks that all counterpossibles are vacuously truethinks about the way we reason counterfactually:

part of the general way we develop counterfactual suppositions is to hold such constitutive [i.e., essential] facts fixed. [Williamson 2007, 164]

It is on these grounds that he thinks that we are sensitive to, for instance, the vacuous truth of (2):

(2) $\neg$ (Gold has atomic number 79) $\square \rightarrow \perp$.

If all counterpossibles are vacuously true, therefore, $(e m r-2)$ is, among the reliable-on the current horn's assumption-and operationally effective rules, ideally informative:

(emr-2) When evaluating $(P \square \rightarrow Q)$, imagine away as few truths as possible compatibly with complying with:

12. Sometimes-as in: "If Nicotine were human, she would have blood"-the judgement could be judged to be correct (if we charitably ignore what are perhaps relevant differences between judging $x$ to be true and judging it to be vacuously true) but the rule is still highly unreliable. I don't need to enter this debate here. 
(c) Preserve consistency; ${ }^{13}$ so long as doing so does not require you to imagine away any essential fact (conditionalized or not, and particular or not) and

(d) If all the essential facts are consistent with $P$, then, imagine away $p 1$ over $p 2$ whenever:

(d.1) $p 1$ is a (non-essential) particular fact and $p 2$ is a nomic or a mathematical or an essential or a conceptual fact. ${ }^{14}$

(d.2) $p 1$ is a nomic fact and $p 2$ is a mathematical or an essential or a conceptual fact.

(d.3) $p 1$ is a mathematical fact and $p 2$ is a conceptual fact. ${ }^{15}$

If $p 1$ and $p 2$ are of the same kind, it won't make a difference to overall similarity which one you imagine away.

(When the antecedent of $(P \square \rightarrow Q)$ is metaphysically impossible, therefore, all actual truths are cotenable.)

How does this bear on $(\neg i)$ ? As an advocate of the vacuous truth of all counterpossibles, Williamson endorses the following equivalences:

(口) $\square A \equiv \neg A \square \rightarrow \perp$

$(\diamond) \quad \diamond A \equiv \neg(A \square \rightarrow \perp)$

(emr-2) constrains what we can imagine away or must hold fixed in hypothetical reasoning. Suppose that $(\neg A \square \rightarrow \perp$ ) is true; so $\neg A$ is metaphysically impossible and the counterfactual, therefore, a counterpossible. For the sake of specificity (and without loss of generality), suppose that it is (2) above.

Suppose-as Williamson thinks - that we have the capacity to know that (2) is vacuously true. This implies that, in evaluating (2), we would hold fixed "Gold has atomic number 79" despite the fact that it contradicts the antecedent of (2). Looking back at (emr-2), and especially at clause (c), the suggested explanation of why, in acquiring knowledge of (2), we hold that fixed is that we are sensitive to the essentiality of "Gold has atomic number 79". Generalizing, the suggested explanation is that we have the capacity to know about the truth of vacuously true counterpossibles and to know that the negations of their antecedents are metaphysically necessary because we have a capacity for essentialist knowledge.

13. Doable only when $P$ is not logically contradictory itself.

14. If mathematical or conceptual facts are essential-as one might plausibly endorsethere is redundancy in (d.1) and (d.2). But redundancy won't do any harm here (and the intensional differences might be serviceable, as $\S 3$ will put us in a position to see). In addition, for the reasons in footnote 7 , if mathematical facts were believed to be necessary yet not essential, (d.1) should begin with ' $p 1$ is a non-essential and non-mathematical, particular fact'.

15. This clause must (and can) be included only if mathematical facts are believed not to be essential. 
Indeed, according to Williamson, the judgement that something is metaphysically necessary is the output of evaluating counterpossibles together with the fact that holding fixed essential facts "is part of our general way of assessing counterfactuals" [Williamson 2007, 170]. (Note an additional disagreement between Kment and Williamson: only according to Williamson are all particular essential facts necessary; in line with his necessitist views.)

Now, even if the suggested explanation were correct, it being so falls admittedly short of supporting $(\neg i)$. All it supports is that the knowability of at least some counterfactuals depends on our essentialist vision. But $(\neg i)$ requires it to be so for at least most counterfactuals. How, then, could Williamson's work provide grounds for thinking that $(\neg i)$ might be true? Not only does Williamson think that (some) counterpossibles, like (2), are accessible to us but also that, in evaluating counterfactuals of the form of (2), our reasoning is:

subject to the same constraints, whatever they are, as counterfactual conditionals in general, concerning which parts of our background information are held fixed. [Williamson 2007, 163-164]

No matter whether the counterfactual at hand is a counterpossible or not, or of the form of (2) or not, therefore, one same rule-encoding the relevant cotenability priority order-governs our hypothetical reasoning in general. Williamson is particularly explicit about this in [Williamson 2007, 171]. There, he considers the objection that a capacity to know ordinary counterfactualstypically not counterpossibles and typically with consistent consequent-need not amount to a capacity to know counterfactuals of the form $(A \square \rightarrow \perp)$. The response he offers is to the effect that it does amount to it. For the reasons above, if we are sensitive-as we are according to Williamson- to the vacuous truth of counterpossibles like (2) - which is of the form $(A \square \rightarrow \perp)$-those general constraints must be akin to $(e m r-2)$. Since one same rule governs hypothetical reasoning, then, independently of whether the counterfactual at hand is a counterpossible or not, or has consistent consequent or not, $(\mathrm{emr}-2)$, or a rule equivalent to it, is the rule that constrains our hypothetical reasoning also when we evaluate ordinary counterfactuals.

When applying (emr-2) in counterfactual reasoning, we have to proceed in two steps: (1) determine whether the negation of the antecedent is (or is metaphysically implied by) an essential fact, (2) only if it is, hold it fixed. Paralleling Kment's reasoning above, therefore, the belief that this might induce is that we routinely deploy our capacity for essentialist knowledge in evaluating counterfactuals (whether ordinary or not); contra $(i)$. This is a prima facie case against (i) that no one who believes in the vacuous truth of all counterpossibles should overlook. Also in this case, I want to resist it in $\S 3$.

This concludes my prima facie two-horn case against (i). 


\section{Reinstating ( $i$ )}

In this section, and granting that either (emr-1) or (emr-2) encode the correct cotenability priority order (i.e., granting Graphic 1), I argue that (i) should be reinstated. The conclusion I'm after is correspondingly two-horn: whether or not one believes in false counterpossibles, $(i)$ is in good standing. I'll achieve this conclusion by arguing that:

(ii) (Granted Graphic 1) Essentialist blindness would preclude the knowability of some counterfactuals but not most-for a substantial body of counterfactuals, it would not preclude their knowability.

(i) follows from (ii). For (i) says that a capacity for essentialist knowledge is not a core capacity for counterfactual knowledge and (ii) says that too and, in addition, that our essentialist vision-if we have it-is a counterfactual-specific capacity. Arguing for (ii), therefore, will be my vindication-strategy. The extra content of (ii) will be used in $\S 4$.

The argument to follow is somehow complex, because I aim at an argument that can be found persuasive irrespective of one's views on the truth-value of counterpossibles. (emr-1) and (emr-2) are statements of the two ideally informative rules for counterfactual reasoning that, respectively, a believer and a disbeliever in false counterpossibles can reasonably endorse. The reason for this is that (emr-1) would make us track the sometimes truth and sometimes falsity-under the first horn's assumption-of counterpossibles, and (emr-2) would make us track their always being vacuously true-under the second horn's assumption. For the reasons in § 2, I grant that, in order to acquire knowledge of a given counterfactual, the evaluator has to behave according to (emr-1) [or else (emr-2)] in an informed manner. The main idea in the argument below is that, even if we suffered from essentialist blindness, we could still informedly behave according to (emr-1) [or else (emr-2)] when evaluating many counterfactuals; enough of them as to undermine $(\neg i)$.

There are two sources of essentialist blindness-the phenomenon of being blind to the essentiality of essential facts-relevant for current purposes:

(Con) Due to conceptual impoverishment; suffered by those who lack essentialist notions, thereby being not even enabled to grasp essentialist thoughts-let alone to acquire essentialist knowledge.

(Cog) Due to cognitive impoverishment (broadly understood); suffered by those who, while conceptually equipped to grasp a true essentialist thought (like $\left\ulcorner a\right.$ essentially $\left.\phi^{\prime} s\right\urcorner$ ) are nonetheless not cognitively equipped to know that it is true. ${ }^{16}$

16. Equivalently: suffered by those who, while conceptually equipped to entertain essentialist thoughts, are not cognitively equipped to know, of an essential truth-like (allegedly) water is composed of $\mathrm{H}_{2} \mathrm{O}$ - that it is an essential truth. 
Given these two potential sources, and given what kind of argument I aim at, this is its structure:

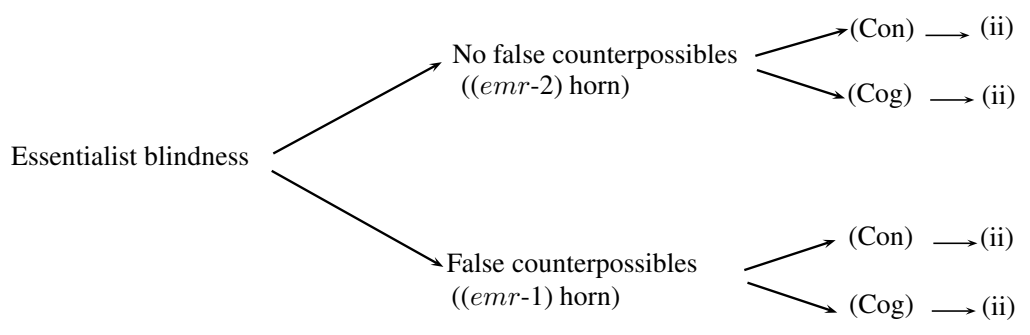

\subsection{The case for those who believe that all counterpos- sibles are true; the $(\mathrm{emr}-2)$ horn}

Suppose that all counterpossibles are vacuously true. Suppose also-borrowing one of Williamson's everyday examples-that in our world a rock falls down a slope and, instead of ending in the lake at the bottom, it rolls into a bush. Suppose further that (3) is true:

(3) If the bush had not been there $[P]$, the rock would have ended in the lake $[Q]$.

The (emr-2) +(Con) case. Could, in evaluating (3), a (Con)-evaluator behave according to (emr-2) in a knowledge-conferring manner? I think she could (assuming minimal logical skills). One lacking essentialist notions is compatible with one being guided (in hypothetical reasoning) by the non-crossed-out portion of $(e m r-2):^{17}$

(emr-2) When evaluating ( $P \square \rightarrow Q)$, imagine away as few truths as possible compatibly with complying with:

(c) Preserve consistency so long as doing so does not require you to imagine away any essential fact (conditionalized or not, and particular or not); and

(d) If all the essential facts are consistent with $P$, then, imagine away $p 1$ over $p 2$ whenever:

(d.1) $p 1$ is a particular fact and $p 2$ is a nomic or a mathematical or an essential or a conceptual fact.

(d.2) $p 1$ is a nomic fact and $p 2$ is a mathematical or an essential or a conceptual fact.

17. In relation to fottnote 14 , this is why the intensional differences might be useful despite a potential redundancy. 
(d.3) $p 1$ is a mathematical fact and $p 2$ is a conceptual fact.

If $p 1$ and $p 2$ are of the same kind, it won't make a difference to overall similarity which one you imagine away.

$P$ is the negation of the-by assumption-actual truth 'the bush is there' $(\neg P)$. Can the conceptually-impoverished evaluator imagine ' $\neg P$ ' away? Yes, because " $\neg P$ " contradicts the antecedent and-we theorists know-it is not an essential fact. But would she imagine it away? Yes, because " $\neg P$ " contradicts the antecedent and, despite her lacking essentialist notions, she is following a portion of (c) that asks her to do so. Next: Where would the rock end? If she knew that "the rock ends there" is a particular fact, and if she knew also that "rocks slide down sufficiently steep slopes like this unless there's something on their way to stop them" is a nomic fact, she would (be in a position to) knowledgeably follow (d.1), thereby imagining away "the rock ends there" and imagining in "the rock ends in the lake". This blind evaluator would therefore act according to (emr-2) despite her (Con)-blindness.

I conditionalized twice with 'If she knew'; once, on her knowing that certain facts are particular facts; the other, on her knowing about nomic tendencies. Those antecedents might not be true on occasions. For my argument to go through, however, I don't need the antecedents to be true. If the conditionals are true-as I intend them to be so-recognized-then, as far as evaluating (3) is concerned, informedly acting according to the seen portion of (emr-2) does not require essentialist notions. In addition, the evaluator's behaviour amounts to acting according to (emr-2).

Similar conclusions apply in the cases of other uncontroversial counterfactuals-typically not counterpossibles and with consistent consequent. I omit the statement of analogous treatments but one might want to explore other cases like, for instance:

(4) If I were there, I would be there.

(5) If I were a seven-year-old human, I would have blood.

(6) If I had flipped the coin, it would most likely end up in tails or heads.

(7) If I ate an Amanita Phalloides I would be severely poisoned.

Consequently, the impoverished rule that the conceptually impoverished evaluator follows is, for a big enough body of counterfactuals, a sufficiently reliable guide to counterfactual truth. Provided that she responsibly acts according to the portion of $(e m r-2)$ she has conceptual resources to see, the output of so doing will be a true and informed judgement. If my belief that I have hands counts as knowledge, those counterfactual judgments should count as knowledge too.

So far, of (ii), I've motivated this much (for the (emr-2) +(Con) case): for a substantial body of counterfactuals, essentialist blindness would not preclude their knowability. I will next argue that: it would nonetheless preclude the knowability of some. 
Our conceptual impoverishment would block-in the current case-the knowability of at least some counterpossibles as well as that of some noncounterpossibles. Consider first counterpossible (2):

(2) $\neg$ (Gold has atomic number 79) $[\neg P] \square \rightarrow \perp[Q]$.

Could, in evaluating (2), a conceptually impoverished evaluator behave according to (emr-2) in a knowledge-conferring manner? I think this time she could not. $\neg P$ is the negation of the-by assumption—actual and essential truth 'Gold has atomic number 79'. Can the conceptually-impoverished evaluator imagine ' $P$ ' away? No, because it is an essential fact and, as per (c), it must stay. But would a responsible such evaluator imagine it away? Yes, because it contradicts the antecedent and, according to the bit of (c) she sees, it must be imagined away. The conceptually-impoverished evaluator would therefore preserve consistency, thereby judging (2) to be false. However, (2) is true-all counterpossibles are true in the current case. The evaluator would therefore arrive at a false judgement. ${ }^{18}$ Similar conclusions apply in the case of many other counterpossibles. ${ }^{19}$

If Kment's treatment of (8) below is correct [Kment 2006, 289], there are also counterfactuals that are not counterpossibles and that are also epistemically inaccessible for a conceptually-impoverished evaluator:

(8) People use a certain colourless, odourless, tasteless liquid that is not composed of hydrogen and oxygen to quench their thirst, etc. $\square \rightarrow$. People use a liquid other than water.

Kment thinks that, in evaluating (8), we-as a matter of fact-behave as follows: we imagine away the actual and non-essential truth that 'water is the colourless, odourless, tasteless liquid that people usually use to quench their thirst, brush their teeth, etc.' and we hold fixed instead the actual and essential-or so let us grant-truth 'if water exists, it is composed of hydrogen and oxygen'. (Note that they are individually consistent yet jointly inconsistent with the antecedent, so exactly one must go.) He then explains why we-as a matter of fact-behave as we do by appealing to our essentialist vision; in particular, to our knowledge that 'if water exists, it is composed of hydrogen and oxygen' is an essential truth. The knowability of this Putnam-style example would be precluded too if we suffered from (Con)-blindness.

18. Any behaviour according to (c) under the illusion that one has to behave according to the seen portion of (c) would be blame-worthy in the case of (2) and, as such, knowledge-destroying.

19. Sometimes—as in " $\neg$ (Gold has atomic number 79) $\square \rightarrow 2+2=4$ " - the judgement that a counterpossible is true might be argued to amount to knowledge; provided one is charitably not too picky about that judgment not (possibly) taking into account its being vacuously true. Whether those judgements amount to knowledge is controversial, but I don't need to decide these cases here. If they do, they provide additional support for the previous bit of (ii) I argued for. And to argue for the bit of (ii) I'm currently arguing for, it suffices that sometimes - as in (2)—the judgement be uncontroversially incorrect. 
We can sum up as follows. Examples (2) and (8) - granting Kment's diagnosis of the latter-show that, sometimes, the conceptually impoverished evaluator might have a dilemma as to whether or not to imagine a given fact away that would critically require (the proper exercise of) her essentialist vision to solve it in a knowledge-conferring manner. Example (3) - and, by extrapolation, (4)-(7)—suggests, however, that many (ordinary) counterfactuals will not generate such critical dilemmas. This concludes my argument for (ii) for the $(e m r-2)+($ Con $)$ case.

The (emr-2) $+(\operatorname{Cog})$ case. The ( $\mathrm{Cog})$-type counterfactual evaluator sees-let us assume, so that the case is interestingly different from the previous onethe whole of $(e m r-2)$ but is cognitively impoverished. Now, knowledge that $X$ is not an essential fact is compatible with (Cog)-type essentialist blindness. ${ }^{20}$ Therefore, there are non-counterpossibles such that, when evaluating them, one can knowledgeably follow (c) compatibly with being blind to the essentiality of essential facts. Let me elaborate on this by focusing on (3). A (Cog)-type evaluator can know that the presence here of this bush is essential neither to the bush nor to the place without knowing, of any essential fact, that it is an essential fact. "The bush is there" would therefore be imagined away. Next: Where would the rock end? If she knew that "the rock ends there" is a non-essential particular fact, and if she knew that "rocks slide down sufficiently steep slopes like this unless there's something on their way to stop them" is a nomic fact, she would (be in a position to) knowledgeably follow (d.1), thereby imagining away "the rock ends there" and imagining in "the rock ends in the lake". The counterfactual would correctly be judged to be true. As above, I intend this example to be generalizable to a substantial body of non-counterpossibles, among which (4)-(7). For reliability reasons as above, these informed true judgements should count as knowledge.

Things are otherwise with (this time: all) counterpossibles. If "Gold has atomic number 79" is an essential fact, one cannot know that it is not (by facticity of knowledge). And a (Cog)-evaluator cannot know either that it is essential. Under these circumstances, any behaviour according to (c) - the whole of which is now seen-when evaluating (2) would be knowledge-undermining. The discussion of (8) above applies in the (Cog)-case too.

By now, therefore, we have enough reasons for (ii) also in the (emr$2)+(\operatorname{Cog})$ case. Nonetheless, it will be helpful to discuss here (9) as well:

(9) If Wittgenstein and Betty Hutton had had a child $[P], \mathrm{s} /$ he would be essentially human $[Q]$.

Compared to (2) and (8), its distinctive feature is that it overtly involves essentialist notions. As a result, it would be ungraspable by a (Con)-evaluator but not

20. Knowledge that I'm not an essentially standing being (e.g., on the basis of my being sitting or having sat) is compatible with blindness as to which the essential facts are. 
by a (Cog)-one. Even if graspable, it remains unknowable. If $S$ knew that ' $\neg P$ ' is a non-essential particular fact, she would act according to clause (c) and imagine it away. Next: would the child be essentially human? The child is essentially human in the closest $P$-worlds if and only if 'All humans are essentially so' is an actual truth. The epistemic priority here lies on the right-hand side: unless $S$ knows whether 'all humans are essentially so' is actually true, she won't know whether the child is essentially human in the closest $P$-worlds.

This concludes the first half of the argument.

\subsection{The case for those who believe that there are false counterpossibles; the (emr-1) horn}

Suppose that there are false counterpossibles. Consider (3) again:

(3) If the bush had not been there $[P]$, the rock would have ended in the lake $[Q]$.

The (emr-1) + (Con) case. Could, in evaluating (3), a conceptually-impoverished evaluator behave according to (emr-1) in a knowledge-conferring manner? I think she could. As above, conceptual impoverishment of the kind at issue is compatible with one being nonetheless sensitive to the non-crossed-out portion of $(e m r-1)$ :

(emr-1) When evaluating $(P \square \rightarrow Q)$, imagine away as few truths as possible compatibly with complying with:

(a) Preserve consistency; and

(b) Imagine away $p 1$ over $p 2$ whenever:

(b.1) $p 1$ is a non-mathematical particular fact and $p 2$ is a nomic or a mathematical or a conditionalized-essential or a conceptual fact.

(b.2) $p 1$ is a nomic fact and $p 2$ is a mathematical or a conditionalized-essential or a conceptual fact.

(b.3) $p 1$ is a mathematical or a conditionalized-essential fact and $p 2$ is a conceptual fact.

If $p 1$ and $p 2$ are of the same kind, it won't make a difference to overall similarity which one you imagine away.

Except for 'non-mathematical'-which makes no significance difference-the remaining bit is identical to what remained in the case of (emr-2). Consequently, the conceptually-impoverished yet responsible evaluator would behave exactly as above: she would imagine away $(\neg P)$ and "the rock ends there". But should she behave like that? Yes. $(\neg P)$ should be imagined away according to clause (a) and "the rock ends there" should be imagined away according to (b.1). Similar 
conclusions apply in the case of many other everyday counterfactuals like (4)(7). Also in this case, therefore, the output will be a true and informed judgement that should count as knowledge.

This case differs from the previous (Con)-case in that, according to clause (a) - but not according to clause (c) - the negation of a given antecedent should be imagined away irrespective of whether it is an essential fact. As far as counterpossibles are concerned, therefore, there are even fewer chances for the conceptually-impoverished evaluator to deviate from the demands of (emr-1). A current assumption is that there are false counterpossibles, and (2) is a best candidate to be an instance of the (content of the) assumption. By the reasons in the previous (Con)-case, it will be judged to be false by the conceptuallyimpoverished evaluator, provided she is responsibly acting according to the part of the rule she sees. So it will be known to be false.

In relation to (ii), therefore, and for the current (Con)-case, we have enough material to conclude that, for a substantial body of counterfactuals (now including some counterpossibles), essentialist blindness would not preclude their knowability. To conclude my argument for (ii) for this case, I should next argue that it would nonetheless block the knowability of some of them. To this effect, it suffices to note that the reflections above on counterfactual (8)—granting Kment's diagnosisapply here as well.

The $(e m r-1)+(\operatorname{Cog})$ case. This is the fourth and final case. Ordinary counterfactuals like (3)-(7) will be knowable also by this (Cog)-evaluator that sees the whole of $(e m r-1)$. This is even more straightforward in this case than in the $(e m r-2)+(\operatorname{Cog})$ one, since $(e m r-1)$ leaves less space for what we referred to above as critical dilemmas (i.e., dilemmas that require essentialist vision to solve them knowledgeably). One can see this by comparing clauses (a) and (c). By parity of reasoning, therefore, also in this case we get that for a substantial body of counterfactuals (also including some counterpossibles now), essentialist blindness would not preclude their knowability.

For reasons strictly analogous to those in the previous (Cog)-case, counterfactuals along the lines of (8) and (9) are epistemically inaccessible to (Cog)evaluators also under the (emr-1)-assumption. Therefore, (Cog)-essentialist blindness would block the knowability of some counterfactuals.

This concludes the second half of the argument.

If the argument in this section is persuasive, then, irrespective of whether we are sympathetic to the cotenability priority order encoded in $(e m r-1)$ or to the one encoded in (emr-2), we have no good reason to think that $(i)$ is false. This concludes my two-horn defence of it. 


\section{Consequences for Kment's and Williamson's views on the relation between modality and counterfactuals}

It emerges from $\S 3$ that no view on the truth-value of counterpossibles by itself incurs commitment to $(\neg i)$. This is good news; especially if $(i)$ is agreed to be the default claim. The discussion there, however, puts us in a position to realize-or so I wish to motivate next-that certain evolutionary explanations that Kment and Williamson provide are unsatisfactory.

Kment and Williamson appeal to the evolutionary usefulness of counterfactual knowledge with a view to achieving several explanatory goals. Among them (see [Williamson 2007, 134-136] and [Kment 2006, 243, and 288-290]):

(EG.1) Explaining the emergence of our metaphysical modal notions and thought (Kment and Williamson)

(EG.2) Explaining the existence of our capacity for metaphysical modal knowledge (Kment and Williamson)

(EG.3) Subsuming the epistemology of metaphysical modality under the epistemology of counterfactuals (Williamson).

Consider now these similar goals one could have:

(EG.4) Explaining the emergence of our essentialist notions and thought

(EG.5) Explaining the existence of our capacity for essentialist knowledge

(EG.6) Subsuming the epistemology of essence under the epistemology of counterfactuals.

And consider these two tasks:

(*) Meeting (EG.4)-(EG.6) without having $(\neg i)$ available

$(* *)$ Meeting (EG.4)-(EG.6) by appealing to $(\neg i)$

In order to identify what I believe to be argumentative gaps in Williamson's and Kment's ways of achieving (EG.1)-(EG.3), I'll proceed as follows. First, I'll show that $(* *)$ is considerably easier than $(*)$. Second, I'll show how that bears on (EG.1)-(EG.3) in the context of Kment's and Williamsons' accounts.

$(* *)$ is easier than $(*)$. Knowledge of ordinary (and uncontroversial) counterfactuals like (7): "If I ate an Amanita Phalloides I would be severely poisoned" have a very good claim to be evolutionarily useful. If $(\neg i)$ were true, knowledge of most ordinary counterfactuals like (7) would already require a capacity for essentialist knowledge. Consequently, the fact that knowledge of them is evolutionarily advantageous would suffice to, on those grounds, meet the goals 
(EG.4)-(EG.6) by means of an evolutionary explanation. But if ( $i$ ) is true-and thereby $(\neg i)$ unavailable-considerably more needs to be done to meet those goals by those means. Let me elaborate.

As noticed in $\S 3$, (ii) implies not only $(i$ ) but also that a capacity for essentialist knowledge-if we have it-is a counterfactual-specific capacity. Supposeas engagement in (EG.4)-(EG.6) presupposes-that we enjoy essentialist vision. Let $C$ be the set of all counterfactuals that we are conceptually enabled to know (and therefore have conceptual resources to entertain). The claim that our capacity for essentialist knowledge is counterfactual-specific implies that there is a non-empty proper subset of $C$-let's call it '(DepEss)'-that is exactly the set of counterfactuals from $C$ whose knowability depends on us not being blind to the essentiality of essential facts. Let us call the complementary subset '(NotDepEss)'. Consider now the following claim:

(iii) Our (hypothetical) essentialist blindness would have (had) no negative effect on our survival or reproduction chances because epistemic access to the elements in (DepEss) is evolutionarily irrelevant (or, at any rate, redundant). Rather, it is epistemic access to (some of) the elements of (NotDepEss) that makes the evolutionary difference in view (or, at any rate, that suffices for it).

In the absence of $(\neg i)$, and in order to meet (EG.4)-(EG.6) by means of an evolutionary explanation, one must argue that (iii) is false. Now, belief on what the elements of (DepEss) are depends on whether one believes in false counterpossibles or not. As we saw in $\S 3$, if one disbelieves in false counterpossibles, (DepEss) should be believed to include virtually all non-trivial counterpossibles, Putnam-style counterfactuals like (8)—granting Kment's diagnosis-and counterfactuals like (9). If one believes in false counterpossibles, those (false) counterpossibles are arguably excluded from (DepEss). But in each case, (DepEss) contains elements whose knowability is independently controversial-let alone their evolutionary usefulness. Many ordinary counterfactuals like (7)—with possible antecedent-are plausibly known and plausibly evolutionarily useful. But these counterfactuals fall, in all cases, under (NotDepEss). ${ }^{21}$ To successfully argue against (iii), one would need to argue that we (the species) know some elements in (DepEss) - enough of them to ground evolutionary explanations-and that knowledge of them is (or has been) evolutionarily useful. Given what-on the basis of $\S 3$-we can expect the elements of (DepEss) to be-on each of the two ( $\mathrm{Cog}$ )-horns-this is a very difficult task; certainly considerably harder

21. Let me say in passing: My explanation why the knowability of ordinary counterfactuals like (3)-(7) is not controversial is two-fold. First, they are epistemically accessible even when guided by some impoverished rule and, second, they are counterfactuals on which (emr-1) and (emr-2) agree. They are, therefore, among the agreed data. To rest one's case on controversial counterfactuals is a more demanding task. (See [Roca-Royes 2011] for a related point.) 
than $(* *)$, especially given that everyday counterfactuals like (3)-(7) are not in (DepEss).

How does this bear on (EG.1)-(EG.3)? Each of (EG.1)-(EG.3) speaks of metaphysical modality. Here, I need to separate the case of metaphysical necessity from that of metaphysical possibility. I begin with the former. The conditionalized-essential facts that $(e m r-1)$ mentions are metaphysically necessary according to Kment, and so are, according to Williamson, the essential facts that (emr-2) mentions. With this in mind, one can now retrospectively check that, mutatis mutandis, and by their respective lights, the arguments in $\S 3$ apply to the property of metaphysical necessity as well. As a result, by their lights (especially: by what each takes the metaphysical necessities to be):

(iv) (Granted Graphic 1) Blindness to the metaphysical necessity of metaphysically necessary facts would preclude the knowability of some counterfactuals but not most-for a substantial body of counterfactuals, it would not preclude their knowability.

To satisfactorily achieve (EG.1)-(EG.3) by means of an evolutionary explanation for the case of metaphysical necessity, therefore, Kment and Williamson would need to argue that we (the species) know some elements in (DepEss)—enough of them to ground evolutionary explanations-and that knowledge of them is (or has been) evolutionarily useful. That difficult task, however, as far as I've been able to see, has been carried out by none of them. This reveals what I believe to be a considerable argumentative gap in their respective accounts.

Provided that my arguments in relation to metaphysical necessity are persuasive, we now got to a dialectical point where I think that it wouldn't add much to unfold the case of metaphysical possibility. For-that proviso in placeKment's and Williamson's accounts, as they (seem to) stand, support, at most, a counterfactual-based evolutionary explanation for the case of metaphysical possibility only. This, for some (and I believe Kment and Williamson to be included here), would be a disappointingly less philosophically significant result.

Despite not needing to elaborate much on this: I think that similar conclusions as above apply in the case of metaphysical possibility all the same. I shall just offer a hint as why I think so: none of the arguments in $\S 3$ that were aimed at showing that-whichever the case-ordinary counterfactuals like (3)(7) belong to (NotDepEss) exploited at any point the evaluator's sensitivity to the metaphysical possibility of metaphysically possible facts either.

On the basis of $\S \S 3-4$, therefore, and as far as we've been given reasons to believe, it might still be that essentialist and metaphysical modal thought can be "removed from our conceptual scheme without collateral damage", contrary 
to what Williamson argues [Williamson 2007, 136] and Kment suggests [Kment 2006, § 7]..$^{22,23}$

\section{Bibliography}

FINE, KIT

1994 Essence and modality, in Philosophical Perspectives 8: Logic and Language, Atascadera, CA: Ridgeview, 1-16.

HALE, BOB

2002 Knowledge of possibility and of necessity, in Proceedings of the Aristotelian Society, 103(1), 1-20.

ICHIKAWA, JONATHAN

ms. Modals and modal epistemology.

http://jonathanichikawa.net/papers/mme.pdf, version of 9 May 2011, accessed 17 December 2011.

KMENT, BORIS

2006 Counterfactuals and the analysis of necessity, Philosophical Perspectives, 20(1), 237-302.

LEWIS, DAVID

1973 Counterfactuals, Oxford and Cambridge: Blackwell Publishers, and Harvard University Press.

NOLAN, DANIEL

1997 Impossible worlds: A modest approach, Notre Dame Journal of Formal Logic, 38, 535-572.

22. Jonathan Ichikawa $[\mathrm{ms}$.$] argues that, rather than by appealing to the evolutionary$ usefulness of counterfactuals, one can meet (EG.1) by appealing to the evolutionary usefulness of our capacity to reason modally in general-as opposed to metaphysically modally in particular. I am very sympathetic to his case for this. It remains to be seen, however, how that could contribute towards (EG.2)-(EG.3). The following seems to me to be a plausible, open possibility: that we have the conceptual resources to formulate questions about metaphysical necessity and essence which we do not have the capacity to knowledgeably answer. Elaborating on this, however, falls beyond the scope of the present paper.

23. Thanks to the audiences in Barcelona (Logos Seminar), Lisbon (Research(es) in Epistemology Workshop), London (London Logic and Metaphysics Forum), Nancy (Modalities: Semantics and Epistemology Workshop), Nottingham (VSS), Oxford (Jowett Society) and Sheffield (VSS) for valuable discussions on the topic. Thanks also to my colleagues in Stirling, and to Bob Hale, Jonathan Ichikawa, Margot Strohminger, Tuomas Tahko and Anand Vaidya. Finally, I'm enormously grateful to two anonymous referees for this journal for extremely penetrating comments and helpful suggestions on previous drafts, as well as to the guest editors of this issue, Filipe Drapeau Contim and Sébastien Motta. 
ROCA-ROYES, SÒNIA

2011 Modal knowledge and counterfactual knowledge, Logique et Analyse, 54(216), 537-552.

Williamson, Timothy

2007 The Philosophy of Philosophy, Oxford: Blackwell. 